\title{
Early Delivery of Experimental Organism
}

National Cancer Institute

\section{Source}

National Cancer Institute. Early Delivery of Experimental Organism. NCI Thesaurus. Code C124617.

A birth event that occurs prior to the scheduled c-section date or expected delivery date. 